\title{
THERAPEUTIC HYPOTHERMIA AFTER OUT-OF-HOSPITAL CARDIAC ARREST IN CHILDREN
}

\author{
Jolanta Majer \\ Department of Emergency Medicine, Holy Mary Memorial Provincial Specialist Hospital, Czestochowa, Poland
}

Disaster Emerg Med J 2017; (2)1: 53-54

Dear Sir,

I have read with great interest the recent article by Chang et al. [1] published in "Resuscitation" regarding mild therapeutic hypothermia (MTH) and its outcomes in paediatric patients who survived out-of-hospital cardiac arrest (OHCA). The authors performed a cross-sectional observational study of OHCA patients.

In the study, MTH was defined as therapeutic hypothermia with a core temperature of $32-34^{\circ} \mathrm{C}$ after the return of spontaneous circulation (ROSC). MTH was achieved with different cooling methods, including external cooling (water or ice padding), internal cooling (gastric lavage, bladder cooling or intravascular cooling with the use of a catheter) or mixed approaches [2] (Fig. 1). The minimum duration of MTH was assumed to be 12 hours. Although

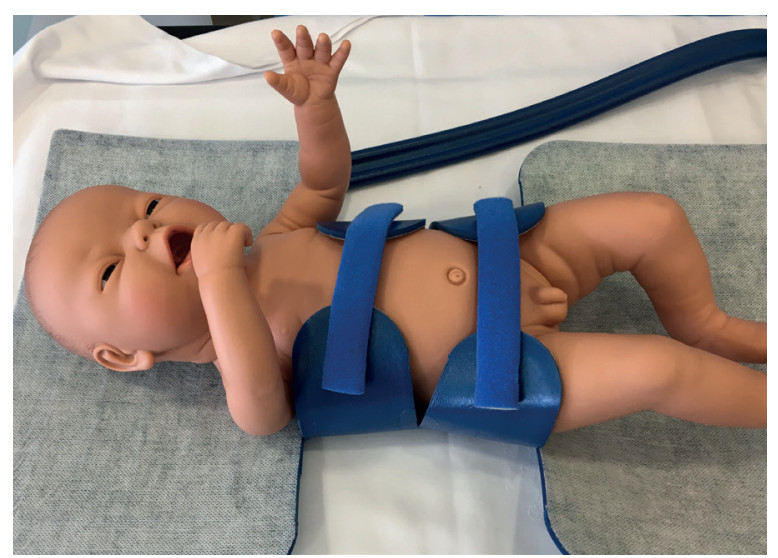

FIGURE 1. Temperature Management System, ARCTIC SUN ${ }^{\circledR}$, Cooling Kit (BARD Medical; Covington, GA, USA) such a procedure is in accordance with the global standards, the current European Resuscitation Council (ERC) guidelines have standardized the rules for applying hypothermia, which should be maintained at $32-36^{\circ} \mathrm{C}$ for at least 24 hours [2].

The methodology of the study may arouse several questions, the answers to which are crucial for the possibility of re-evaluating the study and may affect the proper interpretation of the results achieved by Chang et al. [1].

Firstly, how long was the induction of hypothermia to the target temperature of $32-34^{\circ} \mathrm{C}$ ? As indicated by Wik et al. [3], patients may benefit from MTH started in the prehospital setting and continued upon hospitalization if the treatment is uninterrupted.

Secondly, in what manner and how quickly were the patients warmed up? As plasma electrolyte concentrations, the effective intravascular volume and the metabolic rate can change rapidly during rewarming, the ERC guidelines recommend warming the patient at the rate of $\mathrm{ca} .0 .25-0.5^{\circ} \mathrm{C}$ per hour $[2,4]$.

The next question concerns the temperature maintained in patients treated without MTH. One should bear in mind that maintaining a temperature of $36.5^{\circ} \mathrm{C}$ in patients after ROSC is already an interference with the body's homeostasis and thus can influence the results.

Although, as Chang et al. [1] observed, the majority of patients presented non-shockable rhythms, this is related to the specificity of sudden cardiac 
arrest in children. It should be noted, though, that survival to discharge, as well as good neurological recovery, were better in patients with $\mathrm{MTH}$.

In summary, the use of MTH in paediatric patients after ROSC requires further testing. The results presented by Chang et al. evaluating the outcome in groups with and without MTH, although not statistically significant, suggest there is a benefit in using therapeutic hypothermia in such patients.

Conflict of interest: None declared.

\section{REFERENCES}

1. Chang I, Kwak YHo, Shin SDo, et al. Therapeutic hypothermia and outcomes in paediatric out-of-hospital cardiac arrest: A nationwide observational study. Resuscitation. 2016; 105: 8-15, doi: 10.1016/j. resuscitation.2016.04.021, indexed in Pubmed: 27185217.

2. Nolan JP, Soar J, Cariou A, et al. European Resuscitation Council and European Society of Intensive Care Medicine Guidelines for Post-resuscitation Care 2015: Section 5 of the European Resuscitation Council Guidelines for Resuscitation 2015. Resuscitation. 2015; 95: 202-222, doi: 10.1016/j.resuscitation.2015.07.018, indexed in Pubmed: 26477702.

3. Wik $L$, Olsen JA, Persee $D$, et al. The impact of hypothermia treatment on survival to hospital discharge for patients with out-of-hospital cardiac arrest in the circulation improving resuscitation care (CIRC) trial. Circulation. 2012; 126: A159.

4. Moler FW, Silverstein FS, Holubkov R, et al. THAPCA Trial Investigators, THAPCA Trial Group, THAPCA Trial Investigators. Therapeutic hypothermia after out-of-hospital cardiac arrest in children. N Engl J Med. 2015; 372(20): 1898-1908, doi: 10.1056/NEJMoa1411480, indexed in Pubmed: 25913022. 